\section{"Licenciatura em Educação Básica Intercultural": avanços, desafios e potencialidades na formação superior de professores indígenas}

\author{
Laura Marcela Cubides Sanchez ${ }^{\mathrm{I}, \mathrm{II}}$ \\ Fabiana Soares Fernandes Leal ${ }^{\mathrm{II}, \mathrm{IV}}$
}

https://dx.doi.org/10.24109/2176-6681.rbep.102i261.4446

\section{Resumo}

No Brasil, a partir da Constituição Federal de 1988, a educação indígena e a educação intercultural foram ganhando certa relevância nas agendas governamentais e passaram a ter maior protagonismo nas instituições de ensino superior. Nas últimas duas décadas, em várias universidades públicas do País, foram criados programas de caráter intercultural para a formação de professores indígenas. Este artigo de abordagem analítico-interpretativa enfoca o curso de Licenciatura em Educação Básica Intercultural da Universidade Federal de Rondônia (Unir) e tem como objetivo dar visibilidade a avanços, desafios e potencialidades da formação de indígenas, em relação ao propósito da proposta intercultural no ensino superior. Sua relevância está no fato de que a formação superior de professores indígenas ressignifica uma luta política histórica e representa o ressurgimento de reivindicações educacionais e culturais dessas populações. Este estudo é de natureza exploratória e tem como principal insumo material bibliográfico e documental. As fontes primárias de informação consistiram em documentos legislativos e institucionais, os quais foram revisados tomando por base o conceito de interculturalidade crítica. Foi possível identificar que, em nível institucional, apesar dos potenciais sociais e dos avanços que 
foram obtidos até hoje, ainda existem várias falências que dificultam a forma de proceder e garantir a inclusão e a democratização no ensino superior.

Palavras-chave: ensino superior intercultural; formação de professores indígenas; licenciaturas interculturais.

\section{Abstract \\ "Teaching Degree in Basic Intercultural Education": advancements, challenges and potentialities in the higher education of indigenous teachers}

In Brazil, since the Federal Constitution of 1988, indigenous and intercultural education have gained relevance in government agendas and have been raised to a greater role in higher education institutions. In the last two decades, in various public universities in the country, intercultural programs have been created for the training of indigenous teachers. This article with an interpretative analytical approach focuses on the teaching degree in the Basic Intercultural Education program at the Federal University of Rondônia (Unir), aiming to give visibility to the advancements, challenges and potentialities of the formation of indigenous people, in relation to the purpose of the intercultural proposal in Higher Education. Its relevance is in the fact that the higher education of indigenous teachers re-signifies a historical, political struggle and represents the resurgence of educational and cultural demands of these populations. This study is exploratory and its main input is bibliographic and documentary material. The primary sources were legislative and institutional documents, which were revised based on the concept of Critical Interculturality. Research revealed, at the institutional level, despite the social potentials and the advances that have been obtained until today, that there are still several flaws that hinder ways of proceeding and guaranteeing inclusion and democratization in Higher Education.

Keywords: intercultural higher education; intercultural teacher training; training of indigenous teachers.

\section{Resumen \\ "Licenciatura en Educación Básica Intercultural": avances, desafíos y potencialidades en la formación superior de profesores indígenas}

En Brasil, desde la Constitución Federal de 1988, la educación indígena y la educación intercultural han ido adquiriendo cierta relevancia en las agendas gubernamentales y han cobrado mayor importancia en las instituciones de educación superior. En las últimas dos décadas, en varias universidades públicas del país, se han creado programas de carácter 
intercultural para la formación de profesores indígenas. Este artículo de abordaje analítico interpretativo se enfoca en el curso de la Licenciatura en Educación Básica Intercultural de la Universidade Federal de Rondônia (Unir) y tuvo como objetivo hacer visibles algunos de los avances, desafíos y potencialidades de la formación de indígenas, en relación con el propósito de la propuesta intercultural en educación superior. Su relevancia radica en el hecho de que la formación superior de los profesores indígenas resignifica una lucha política histórica y representa el resurgimiento de reivindicaciones educativas y culturales de estas poblaciones. Este estudio es de naturaleza exploratoria y tiene como insumo principal material bibliográfico y documental. Las principales fuentes de información son documentos legislativos e institucionales, que fueron revisados tomando como punto de partida el concepto y la perspectiva de la interculturalidad crítica. Fue posible identificar que, a nivel institucional, a pesar de los potenciales sociales y los avances que se han obtenido hasta hoy, todavía hay varias falencias que obstaculizan la forma de proceder y garantizar la inclusión y la democratización en la educación superior.

Palabras clave: educación superior intercultural; formación de profesores indígenas; licenciaturas interculturales.

\section{Introdução}

As diretrizes políticas da educação devem aludir tanto à transformação das práticas pedagógicas quanto à divulgação de um conteúdo de caráter ideológico que favoreça o andamento das reivindicações das populações historicamente marginalizadas. Tomando por base a perspectiva da Interculturalidade Crítica, a educação intercultural é um projeto social e cultural que tem o compromisso de propiciar cenários à superação de estruturas de dominação colonial que impedem a emancipação e o exercício dos direitos coletivos dos povos indígenas, sob a busca de sua autonomia educacional. Por isso, o ensino superior intercultural emerge como estratégia para promover a participação democrática dessas comunidades e combater as diferentes expressões de exclusão e discriminação vivenciadas não apenas no âmbito universitário, mas em cada um dos campos de ação dos quais, ainda hoje, elas têm pouca representação política e intelectual.

De acordo com a Declaração da Conferência Regional de Ensino Superior na América Latina e no Caribe (Cres, 2018), ao longo da trajetória do ensino superior intercultural, tem surgido uma ampla variedade de experiências de formação acadêmica, dentre as quais se destacam: 1) programas de apoio acadêmico, cotas e bolsas de estudo para a inclusão de estudantes indígenas e afrodescendentes nas instituições de ensino superior (IES) convencionais; 2) projetos de docência, pesquisa e vinculação social, realizados pelas IES convencionais com a participação de indígenas; 3) acordos de cooperação entre IES convencionais e organizações ou comunidades indígenas e 
afrodescendentes; 4 ) universidades ou qualquer outro tipo de IES indígenas ou interculturais, com características diversas, devido às particularidades dos seus contextos; e 5) programas de formação de IES convencionais, criados especialmente para indígenas ou afrodescendentes. Muitos desses estão pensados para a formação de professores que atuam nas escolas dos seus territórios.

Levando em consideração essas informações, é importante enfatizar que o campo de estudo deste artigo se situa na última modalidade apresentada, a qual corresponde aos cursos de licenciatura intercultural, voltados à formação de professores indígenas no Brasil, no marco da Constituição Federal de 1988. Atualmente, esses programas de graduação são oferecidos em mais de 23 universidades federais e estaduais do País. Com isso, esta pesquisa se concretiza no estudo da Licenciatura em Educação Básica Intercultural da Universidade Federal de Rondônia (Unir), apresentando o contexto histórico, social, geográfico e institucional próprio do curso e as particularidades do seu processo de criação, estruturação e andamento. Essa licenciatura funciona desde o ano 2009, na cidade de Ji-Paraná no estado de Rondônia, onde está localizado um dos oito campi da universidade.

Essa temática surgiu do interesse em valorizar o potencial social da presença indígena nas instituições de ensino superior. Dessa forma, o objetivo é visibilizar alguns dos avanços, desafios e potencialidades da formação superior de professores indígenas, em relação ao propósito do ensino superior intercultural de possibilitar um exercício de autonomia política e epistemológica. Para isso, considerou-se importante reconstruir os acontecimentos e as forças sociais que inspiraram o desenho do programa e têm determinado seu funcionamento até hoje. Mediante a revisão da sua trajetória, propõe-se discutir sobre a lógica que tem orientado alguns dos critérios e estratégias utilizadas para tentar garantir tanto o acesso dos estudantes ao conhecimento e às tecnologias da sociedade moderna quanto o fortalecimento de suas cosmovisões, experiências históricas e saberes ancestrais.

Conforme mencionado, trata-se de um artigo de revisão bibliográfica e documental que tem como referencial teórico o conceito de Interculturalidade Crítica de Catherine Walsh (2009), de maneira transversal à análise dos dados. As principais fontes de informação são documentos legislativos e institucionais, como leis, decretos e projetos políticos e pedagógicos, a partir dos quais se apresenta o cenário comunitário, governamental e universitário em que esse curso é circunscrito. As interpretações desse material se apoiam nos aportes de autores latino-americanos contemporâneos que contribuem para a compreensão crítica desse campo de estudo. Portanto, mesmo que o levantamento documental seja o recurso principal desta pesquisa, a revisão bibliográfica representa o referente fundamental na perspectiva que orienta a aproximação ao tema em questão. Desse modo, espera-se que este trabalho possa suscitar futuras pesquisas sobre a importância da formação e participação de professores indígenas no ensino superior. 


\section{A gestação de um projeto comum: antecedentes da Licenciatura em Educação Básica Intercultural da Universidade Federal de Rondônia}

Os estados que compõem a região Amazônica no território brasileiro (Acre, Amapá, Amazonas, Maranhão, Mato Grosso, Pará, Roraima, Rondônia, Tocantins) têm demandado exigências específicas em relação à atenção educacional, devido à densidade populacional indígena e à dificuldade para ter acesso a muitos dos assentamentos em virtude das condições geográficas.

Segundo Lima (2012), nessa parte do País habitam 60\% dos indígenas e perto de $85 \%$ deles estão em áreas rurais, algumas muito afastadas das principais vias de acesso e conectividade com os centros urbanos. O reconhecimento dessas características que configuram o contexto sociocultural de tais populações permitiu que políticas e projetos para o fortalecimento da educação escolar na região passassem a levar em consideração muitas dessas variáveis, influenciando na oferta de programas de formação para professores que atuam nas aldeias.

O estado de Rondônia, anteriormente chamado Guaporé, devido ao rio Guaporé (fronteira natural entre Brasil e Bolívia), está localizado na região Norte do Brasil e limita a oeste com o estado do Acre, a norte com o estado do Amazonas, a leste com o estado de Mato Grosso e a oeste e sul com a República da Bolívia. Sua extensão territorial corresponde a $237.765 .233 \mathrm{~km}^{2}$, o que representa aproximadamente 2,87\% da área total brasileira (IBGE, [2018]).

Segundo dados do Instituto Brasileiro de Geografia e Estatística IBGE ([2018]), a população prevista do estado de Rondônia em 2019 foi de 1.777.225, distribuída em 52 municípios, tornando-o o terceiro estado mais populoso da região. Além da língua portuguesa, estima-se que perto de 26 línguas nativas sejam faladas hoje pelos habitantes desse território. Mais ou menos $12 \%$ das línguas faladas no País estão localizadas em Rondônia (Unir, 2008a). No entanto, conforme Abrantes e Isidoro (2011), existem alguns povos em que a maioria das pessoas não se comunica mais em sua própria língua.

Segundo dados do último censo oficial do IBGE (2012), 0,9\% dos habitantes do estado se consideram indígenas. Rondônia abriga 32 grupos étnicos, entre os quais existem 54 comunidades indígenas, concentradas em 19 terras tradicionais que ocupam $20,15 \%$ da superfície da área estadual (Unir, 2008a). No estado, como em grande parte da região amazônica, a disputa pela posse da terra entre povos indígenas e diferentes segmentos econômicos, respaldados por governos, tem sido o centro de conflitos interétnicos devido a processos de ocupação e colonização que têm se intensificado desde as últimas décadas do século 20 (Freitas, 1999). Muitas comunidades indígenas de Rondônia perderam boa parte de suas áreas de ocupação tradicional e têm sofrido contundentemente os efeitos socioambientais de projetos de intervenção que estão ocultos sob a ideia de progresso e desenvolvimento do País, o que ocasionou despovoamento, readaptação e grandes transformações em nível cultural. 
No princípio da década de 1980, iniciaram-se algumas atividades para a formação de indígenas no magistério de Rondônia, sendo responsável o Conselho Indigenista Missionário (Cimi), que também atuou nos diálogos para estabelecer a implementação de políticas públicas em favor da educação escolar indígena do estado (Isidoro, 2006). Como parte dessa trajetória, o Cimi foi um dos órgãos envolvidos nas discussões para a criação do Núcleo de Educação Escolar Indígena de Rondônia (Neiro) em 1992, no qual também estavam trabalhando a Secretaria de Estado da Educação (Seduc), a Fundação Nacional do Índio (Funai), a Unir, entre outros. Nesse contexto, os primeiros cursos para professores que começaram a ser ministrados foram as oficinas para produção de textos e assessoria linguística.

Nesse mesmo ano, o Instituto de Antropologia e Meio Ambiente (Iama) empreendeu um projeto de formação de professores indígenas (Pnud. Planaforo, 1995). Nessa experiência, foram formados 30 professores que, posteriormente, adquiriram orientação pedagógica para o desenvolvimento de atividades nas escolas das aldeias por profissionais qualificados. Por fim, foram realizados 12 cursos, sendo 6 destinados a professores indígenas pertencentes aos povos acolhidos pelas cidades de Cacoal e Ji-Paraná e 6 nas áreas indígenas de Igarapé Lourdes, Rio Branco e Zoró. De acordo com Venere (2011), a partir daí, em 1994, entidades como o Conselho de Missão entre Povos Indígenas (Comin) passaram a promover cursos para professores indígenas e efetuar levantamentos linguísticos dos povos de Rondônia.

Vale a pena dizer que essas primeiras iniciativas de educação escolar indígena em Rondônia ocorreram de forma descontínua e fragmentada e estiveram a cargo de profissionais que desconheciam as especificidades e a complexidade cultural desses povos (Venere, 2011). No entanto, os primeiros passos após a Constituição Federal de 1988 estavam abrindo caminho para o que mais tarde foi nomeado como Projeto Açaí (Projeto de Magistério Indígena), que constitui um dos antecedentes mais importantes à criação da licenciatura intercultural da Unir.

O Projeto Açaí é um curso específico em nível de ensino médio, que surgiu da necessidade de dar continuidade à formação de professores indígenas em Rondônia. Em meio da urgência dos movimentos indígenas de institucionalizar sua própria educação, mediante uma política pública de educação escolar indígena, a formação de professores que trabalham nas escolas das aldeias tornou-se um dos focos de discussões intensas das quais nasceu a proposta do Projeto Açaí (Rondônia, 2004). Portanto, embora fosse concretizado pela Seduc de Rondônia, esse é o resultado de esforços e reuniões entre líderes e comunidades, ocorridos desde a primeira metade dos anos 90, a partir da fundação do Neiro.

Em 1997, a Seduc solicitou ao Conselho Estadual de Educação (CEE/RO) a aprovação do Projeto Açaí. Após um ano de revisão, o requerimento foi admitido com alguns ajustes (Venere, 2011). Sua criação foi oficializada pelo Decreto Estadual no 8.516, de 15 de outubro de 1998. Em princípio, era um projeto de capacitação, mas, à medida que avançava, foi se transformando 
em um curso de formação exclusivo para habilitar docentes em efetivo exercício de regência na sala de aula, nas quatro primeiras séries do ensino fundamental, das escolas localizadas nos territórios indígenas de Rondônia (Rondônia, 1998). As adequações sob as quais o Conselho Estadual de Educação aprovou o projeto foram desenvolvidas pela Seduc, com a participação ativa das comunidades durante todo o processo formativo do primeiro grupo, sendo elas que elaboraram as linhas básicas e a estrutura do curso e encarregaram-se da gestão do projeto pedagógico.

Assim, em 1998, Rondônia assumiu o compromisso de garantir a formação de professores indígenas do estado, para que eles, além de ensinar, fossem encarregados, de maneira autônoma, da educação escolar em suas respectivas comunidades (Venere, 2011). Esse primeiro projeto abrangeu 33 etnias e contou com a participação de 126 cursistas em todo o estado para atender a demanda de 2.800 alunos que se encontravam entre a $1^{\mathrm{a}}$ e a $4^{\mathrm{a}}$ série de escolas indígenas (Revista Gestão Universitária, 2004). Teve lugar, de forma gradual, nas aldeias dos municípios de GuajaráMirim e Cacoal, com uma duração de cinco anos, período em que os alunos deveriam completar um total de 4.620 horas (2.700 presenciais e 1.920 não presenciais). O curso estava dividido em duas etapas anuais, cada uma de aproximadamente 35 dias, com uma alta intensidade horária (250 horas), prevista para ser executada entre quatro e cinco semanas (Rondônia, 2004).

Quando esse primeiro grupo de professores já estava sendo formado, os docentes indígenas tiveram a iniciativa de criar a Organização dos Professores Indígenas de Rondônia e Noroeste de Mato Grosso (Opiron), dada a necessidade de instaurar mecanismos que permitissem agremiar e interagir em rede. Desde a sua origem, no ano 2000, foi traçado o objetivo de acompanhar e propor ações administrativas, técnicas e pedagógicas para atender as 67 escolas indígenas existentes no estado de Rondônia até aquele momento. De acordo com Alves (2014), uma vez que vários professores começaram a concluir o curso (entre 2004 e 2005), surgiu a necessidade de continuar essa formação e executar um programa em nível superior, que vai se materializar por meio da licenciatura intercultural da Unir.

Entretanto, antes de falar sobre essa nova proposta, é preciso dizer que, após a primeira experiência com o Projeto Açaí I, foram lançados outros dois cursos de magistério nessa modalidade. Demoraram aproximadamente quatro anos para o início da segunda etapa, que ocorreu entre 2009 e meados de 2014. Durante esses cinco anos, o Projeto Açaí II capacitou 136 professores indígenas para que eles pudessem ensinar da $1^{\mathrm{a}}$ à $5^{\mathrm{a}}$ série do ensino fundamental. Ao final dessa etapa, segundo dados da Seduc (2014a), estavam cadastradas 102 escolas indígenas na rede estadual, com 356 professores responsáveis por 3.200 alunos. Como será visto mais adiante, essa segunda etapa se desenvolve juntamente com os primeiros anos da licenciatura intercultural da Unir.

Diferentemente do processo anterior, de maneira quase imediata, deu-se início ao Projeto Açaí III, que ocorreu entre 2014 e 2019. Em setembro deste último ano, 98 professores indígenas completaram a terceira etapa, juntando-se aos mais de 200 docentes formados até então 
pelo Projeto. Segundo a Seduc (2014b), nessa época, estimava-se que 231 professores estavam lecionando em 114 escolas de aldeias de diferentes grupos étnicos.

Posto isso, deve-se ter em mente que esse processo de expansão e crescimento profissional começou a conferir aos professores indígenas um certo prestígio social na comunidade. A possibilidade de estudar em níveis avançados os tornou mediadores culturais porque, além de conhecer aspectos essenciais da cultura de seu povo, estavam conhecendo a cultura dos não indígenas, o que lhes permitiu adotar novos códigos e ferramentas para estabelecer esse intercâmbio e diálogo entre culturas. Ante seus parentes, sua formação estava adquirindo uma conotação associada a um senso de ascensão e poder político, uma vez que isso os colocava em uma posição de líder e gestor, procurados pela comunidade para se encarregar de assuntos que exigiam transitar entre as duas culturas (Alves, 2014). Portanto, ser professor ia muito além da profissão.

\section{O nascimento e os primeiros anos de desenvolvimento da Licenciatura em Educação Básica Intercultural da Universidade Federal de Rondônia}

A Licenciatura em Educação Básica Intercultural da Unir é oferecida no campus de Ji-Paraná, região central do estado de Rondônia. Essa cidade é circundada por 25 municípios que abrigam uma grande diversidade social, cultural e linguística, sendo essa uma das principais razões pelas quais a demanda pelo curso foi gerada nesse local (Unir, 2008a). Começou em 2009, com o propósito de formar e habilitar professores indígenas que já lecionavam em escolas indígenas de ensino fundamental e médio e que já tivessem passado pelo Projeto Açaí I, considerando que até aquele ano somente tinha sido conduzida a primeira etapa (Alves, 2014).

Como esses cursos de magistério, essa licenciatura foi criada em meio a numerosos debates entre organizações indígenas e entes institucionais, em vista da necessidade de formar os docentes das aldeias no nível superior. O movimento que exercia essa pressão sobre as unidades estaduais responsáveis pela educação escolar indígena de Rondônia se intensificou e se fortaleceu depois do Projeto Açaí I. Segundo Neves (2013), os líderes dessa luta foram os povos Gavião (habitantes originários do que hoje é reconhecido como o estado de Mato Grosso) e Arara (pertencentes ao território onde atualmente está situada Ji-Paraná). Graças ao trabalho conjunto e ao vínculo que se forjou entre eles, em direção a esse fim comum, foi possível estabelecer diálogos com a Unir para a criação desse programa, apesar de diferenças e conflitos históricos entre as duas comunidades (devido à terra e à dinâmica de assentamentos) e dos obstáculos de caráter administrativo, reflexo das pautas do contexto político vigente.

Paralelamente, durante o primeiro mandato do ex-presidente Luiz Inácio Lula da Silva (2003-2007), foi lançado o Programa de Apoio a Planos de Reestruturação e Expansão das Universidades Federais (Reuni), 
mediante o qual se fez um grande investimento não só em estruturas físicas, mas também na abertura de novos cursos, na contratação de novos profissionais, em novos projetos acadêmicos dentro dos departamentos etc. (Neves, 2013). Na segunda metade da primeira década do século 21, alguns departamentos da Unir tinham cotas para a apresentação de projetos de programas que poderiam ser instaurados em determinados campi, conforme as demandas locais. Em Ji-Paraná, dentro do Departamento de Ciências Sociais e Humanas, a discussão sobre a criação de um curso diferente dos programas convencionais, como História, Antropologia, Filosofia etc., já estava ocorrendo.

Diante dessa situação, os líderes indígenas que já vinham estabelecendo outros tipos de contatos com alguns docentes universitários assumiram a tarefa de expor as petições do movimento, relativas à formação de professores indígenas, ao chefe desse departamento naquele momento, o professor Justo Nelson Araújo Escudero. Após essa primeira aproximação oficial, um plano de trabalho começou a ser consolidado entre líderes indígenas, docentes e diretores da universidade, para construir a proposta formal do curso e posterior aprovação no Conselho Superior Acadêmico (Consea) da universidade. À medida que esses diálogos progrediam, outros povos da região aderiam à causa.

De acordo com Neves (2013), foram agendados encontros entre eles para pensar de maneira conjunta os campos do conhecimento que deveriam ser considerados no desenho do programa. A partir do que lideranças ou sabedores das comunidades indicavam sobre o que eles queriam que seus filhos e netos aprendessem e do que já começava a ser estipulado na legislação vigente, os professores que acompanhavam o processo foram encontrando pontos de mediação para a construção do projeto pedagógico do curso (PPC). Portanto, embora os não indígenas tenham participado do processo de criação no papel de apoio institucional, o protagonista dessa história é o movimento indígena, pois a pressão e a persistência dele demandaram que a universidade aprovasse a licenciatura.

Dado esse passo, foi agilizada a documentação requerida para que o curso fosse assegurado em termos de orçamento e infraestrutura por meio do Reuni, já que este estimava a quantidade de títulos que poderiam ser outorgados, a contratação de professores etc. Por parte da instituição universitária, o programa estava sendo concebido como um curso finito. O fato de que sua projeção estivesse estimada apenas para a formação de uma turma mobilizou várias comunidades para que fosse reconhecido como um curso regular.

Finalmente o PPC é aprovado pelo Consea, por meio da Resolução $\mathrm{n}^{\circ} 198$, de 18 de novembro de 2008 (Neves, 2009). Seguindo o projeto pedagógico (Unir, 2008b), o processo foi amparado pelo princípio da autonomia universitária, expresso nos artigos 43 e 53 da Lei no 9.394, de 20 de dezembro de 1996. Uma vez oficializada a proposta, na primeira metade de 2009, foi iniciada a chamada de seleção específica para professores indígenas do estado de Rondônia, do sul do Amazonas e do noroeste de Mato Grosso (Couto, [2018]). Desse modo, o primeiro grupo começou em 
2009, o segundo em 2010 e o terceiro em 2011. Esses três vestibulares ocorreram de maneira consecutiva, permitindo a entrada de três turmas (A, B e C) durante esses primeiros anos.

Daí para frente, o curso teve suportes institucionais que facilitaram e fortaleceram sua implementação: a Secretaria de Educação Continuada, Alfabetização, Diversidade e Inclusão (Secadi), o Programa de Apoio à Formação Superior e Licenciaturas Interculturais Indígenas (Prolind) e o Reuni. Conforme mencionado, a licenciatura intercultural nasceu em um departamento que já existia e, portanto, já possuía diretrizes institucionais que não estavam pensadas de acordo com as especificidades que demandavam a gestão e a direção desse novo curso. Três anos depois do início, o curso alcançou maior independência mediante a criação do Departamento de Educação Intercultural - Deinter (Neves, 2013). A partir desse momento, uma voz própria foi adquirida e os mecanismos para uma participação mais autônoma começaram a ser implementados.

Após o ingresso das três primeiras turmas, passaram-se outros três anos para que fosse reativada a seleção de candidatos, uma vez que o Deinter não tinha infraestrutura suficiente para receber novos grupos de estudantes. Assim, somente em 2015 ingressa a turma D (Unir. Deinter, 2014). É pouco comum que situações como essa aconteçam nos programas convencionais, o que pode ser visto como um mecanismo para enfraquecer esse tipo de iniciativa.

Diferentemente dos processos anteriores, o ingresso letivo de 2015 contemplou cotas não apenas para docentes em exercício, mas para aqueles interessados em se formar para ensinar nas escolas de suas aldeias, em resposta às exigências da educação escolar indígena de Rondônia. Essa decisão foi produto de encontros e reuniões com ex-alunos e líderes das comunidades, com os quais foi acordado, mediante extensas discussões, que os vestibulares teriam uma quantidade de vagas exclusivas para candidatos que já tinham experiência nesse campo e outra para aqueles que apenas concluíram o ensino médio, tentando equilibrar os dois cenários.

No Edital $\mathrm{n}^{\circ}$ 1, de 23 dezembro de 2019, com ingresso no ano letivo de 2020 (o mais recente até agora), foi definido um total de 50 vagas, das quais 25 foram ofertadas para formação com ênfase em Ciências da Linguagem e as outras 25 para formação com ênfase em Ciências da Sociedade (Unir. Deinter, 2019). Para cada uma dessas categorias, foram destinadas 15 vagas específicas para professores atuantes (30) e 10 de ampla concorrência (20). Desse modo, em conformidade com os artigos 25 e 31 da Resolução $\mathrm{n}^{\circ} 1$, de 7 de janeiro de 2015, do Conselho Nacional de Educação (CNE) do Ministério da Educação, são priorizados os candidatos que sejam professores indígenas ou que tenham vínculo com o magistério indígena. De acordo com Knapp ([2018]), muitos deles têm contrato com a Seduc e o fato de se formarem estando em serviço já é um aspecto de negociação com a entidade para que possam se afastar durante os dois meses em que devem residir na cidade.

Adicionalmente, vale ressaltar que esse edital se caracterizou pela consideração de novos critérios sociais, geográficos e culturais na aplicação 
do vestibular, a fim de ampliar a inclusão e a cobertura do curso. Um deles aborda a possibilidade de os candidatos participarem de cada uma das fases do processo em locais relativamente próximos de suas aldeias, estabelecendo vários pontos espalhados pelo estado para a execução das provas. Os municípios definidos para a realização dessas fases foram: Ji-Paraná, Ariquemes, Rolim de Moura, Presidente Médici, Cacoal, Vilhena, Guajará-Mirim, Porto Velho e Aldeia São Luiz, os quais têm uma forte concentração de população indígena (Unir. Deinter, 2019).

Apesar de, no início, o curso ter sido fortemente promovido pelos povos Arara e Gavião, na atualidade, além deles, grande parte dos alunos matriculados pertence às seguintes etnias: Surui Paiter, Cinta Larga, Karitiana, Zoro, Sabane, Mamaide, Tupari, Aruá, Sakurabiat, Poruborá, Migueleno, Oro Waram, Oro Waram Xijein, Oron Nao, Oro Mom, Orowari, Oro at, Negarote, Uru-Eu-Wau-Wau, Amondawa, Makurap, Djoromitxi, Kwazá e Kanoé (Couto, [2018]).

Em relação à estrutura e aos pilares básicos do programa, é importante mencionar que objetivos, metodologias e temáticas abordados nele estão orientados por quatro eixos referenciais: autonomia, interculturalidade, sustentabilidade e diversidade (Unir, 2008a). Está previsto para ser concluído em cinco anos, com uma carga horária total de 4.200 horas. É organizado de acordo com o princípio do currículo integrado, com base no que é nomeado como tópicos contextuais (em vez de disciplinas), que são subdivididos em dois ciclos ao longo do curso: nos primeiros três anos, executa-se o Ciclo de Formação Básica, que consiste em 2.500 horas de aula e objetiva habilitar os professores para atuar no ensino fundamental; nos dois anos seguintes, desenvolve-se o Ciclo de Formação Específica, com 1.700 horas. A esse esquema são adicionadas atividades de Prática de Ensino, Estudo nas Aldeias e Estágio Supervisionado, com a finalidade de complementar o processo de formação que compreende o currículo.

Em geral, todas as licenciaturas interculturais no País têm caráter modular e contam com um calendário acadêmico específico. As etapas nas quais os alunos assistem às aulas não correspondem às dos calendários convencionais. Esses períodos são comumente de dois meses por semestre, tempo durante o qual os estudantes devem se submeter a atividades presenciais de maneira intensiva, com aulas pela manhã e tarde, todos os dias da semana. Algumas delas se ajustam ou coincidem com as férias das escolas nas quais ensinam e com os cursos regulares da universidade. Tomando como referência Paladino e Almeida (2012), isso impede uma sólida convivência entre estudantes indígenas e não indígenas, o que dificulta o cumprimento de um dos objetivos do Prolind: interculturalizar a universidade por meio dessas relações cotidianas.

Durante os meses de intervalo entre uma etapa e outra, os discentes devem avançar em suas investigações e em distintos trabalhos designados pelos docentes. É claro que a finalidade dessa modalidade é privilegiar a permanência nas aldeias, pelo maior tempo possível. No entanto, de acordo com Knapp (2018), essa dinâmica distancia os alunos de outros espaços de aprendizagem, como eventos acadêmicos, grupos de estudo, iniciações científicas, biblioteca e mesmo orientações de pesquisa com seus docentes. 
O curso possui um componente denominado Estudos na Aldeia, que faz parte da Pedagogia da Alternância, que define as diretrizes metodológicas desses programas (Couto, [2018]). Por meio dessa disciplina, desenvolvem-se atividades focadas pincipalmente nos aspectos culturais de suas comunidades, coordenadas por eles e pelos docentes do departamento. A maneira como são executadas depende muito dos projetos em andamento e da possibilidade de os professores e alguns grupos de estudantes viajarem para determinadas aldeias para realizar oficinas, encontros de palavra, visitas guiadas etc. Sem dúvida, esse é um dos pontos-chave da proposta das licenciaturas interculturais, porque é responsável em tecer um vínculo entre as universidades e os contextos comunitários dos estudantes.

Por último, a disciplina do Estágio Supervisionado corresponde a um segmento do curso dedicado para que os alunos possam observar e colocar em prática novas aprendizagens em matéria de ensino e gestão escolar indígena. É importante mencionar que, em algumas ocasiões, o estágio é realizado em escolas não indígenas, para que os alunos estabeleçam outro tipo de contato com outras experiências educacionais (Couto, [2018]). Além disso, espera-se que essa conexão também permita que a população não indígena se aproxime dessas outras realidades, que há séculos se estabelecem nesse território e estão mais próximas do que pensam.

\section{Desafios e potencialidades da formação superior de professores indígenas}

Para a seleção e a leitura das informações que compõem esta seção, foi tomado como quadro de referência o conceito de interculturalidade crítica desenvolvido por Walsh (2009). Dentro dos tipos de interculturalidade, essa perspectiva reconhece a alteridade mediante a diferença dos sujeitos e dos grupos sociais subalternizados. No âmbito educacional, as propostas que seguem essa linha consideram dentro da concepção das práticas pedagógicas as noções de contextualização, problematização e transdisciplinaridade. A partir dessa ideia, é possível observar de que maneira e em que medida esse curso da Unir, tanto em seu desenho quanto no andamento do processo formativo que oferece, consegue se apropriar dos princípios da interculturalidade crítica.

Assumindo que em uma cidade como Ji-Paraná, mesmo que esteja rodeada de territórios ancestrais, os habitantes desconheçam ou tenham certos preconceitos sobre os indígenas, uma das principais preocupações e compromissos desse curso se situa em encontrar a forma de garantir aos que estão nesse processo formativo acesso a um mercado de trabalho justo e inclusivo, em regiões em que ainda se exercem a violência e a estigmatização contra a população indígena. Na perspectiva da interculturalidade crítica, não se trata de empreender projetos que promovam tolerância por parte da população civil, mas de restabelecer o sistema de relacionamento com base 
no diálogo entre diversas experiências culturais e sua validade nos vínculos cotidianos (Walsh, 2008). E por isso que na estrutura pedagógica dessa licenciatura se enfatizam os componentes do exercício e gerenciamento de atividades que permitam conhecer não apenas as condições da atenção educacional, mas também as possibilidades de transformação dos contextos.

Diante disso, tem-se dito que uma medida que poderia contribuir seria a intervenção do Estado por meio de uma política de apoio ao retorno de profissionais e técnicos indígenas às suas aldeias (Paladino; Almeida, 2012), gerando programas que assegurem o início de uma prática docente na qual eles possam valorizar e potencializar os conhecimentos adquiridos na graduação e, assim, garantir uma transição coerente e verdadeiramente impactante nos campos de ação. No entanto, partindo do conceito de interculturalidade adotado, não é suficiente executar medidas de natureza excepcional ou temporária que abordem o tema, senão refundar o Estado, em termos de uma nova lógica e disposição das instituições que o representam (Walsh, 2008), diante do acompanhamento e da atenção para essas populações.

Por enquanto, a partir de cada departamento em que se inscreve uma licenciatura intercultural, está trabalhando-se em mecanismos de participação e avaliação que permitam um repensar constante do curso e uma aproximação maior dos ideais propostos. Em concordância com o PPC da Licenciatura em Educação Básica Intercultural da Unir (Unir, 2008a), esses programas de caráter diferencial são avaliados, com certa periodicidade, por suas respectivas instituições educacionais, com base em três dimensões: (1) avaliação do curso, que inclui a revisão das etapas e o trabalho dos docentes; (2) avaliação nas comunidades, para observar se os trabalhos realizados dialogam com as realidades locais; e (3) avaliação dos discentes, a fim de conhecer os resultados de seu processo de formação.

Esse tipo de estratégia tem possibilitado identificar algumas das dificuldades mais estruturais não apenas para a inclusão de estudantes indígenas, mas também para sua permanência. Fazendo uma leitura geral sobre a trajetória das licenciaturas interculturais no País e tomando Knapp (2018) como referência, sabe-se que alguns dos problemas mais recorrentes para a inclusão estão circunscritos a: (1) distanciamento dos alunos de assuntos burocráticos, como o preenchimento do Currículo Lattes, o desenho de projetos de pesquisa etc.; e (2) domínio de material bibliográfico com linguagem e conteúdo pouco pertinentes às realidades comunitárias. A forma como a interculturalidade é trabalhada depende dos critérios que influenciam o desenvolvimento cultural de um grupo social e da prioridade outorgada a outras realidades em relação com a cultura dominante. Portanto, isso indica que os parâmetros do ensino superior convencional, de acordo com o crivo da ciência ocidental, prevalecem sobre as prioridades dos povos indígenas.

No tocante à permanência, alguns dos pontos mais cruciais estão registrados: (1) na falta de garantias à concessão de bolsas, devido 
à ausência de políticas públicas específicas que garantam recursos econômicos suficientes para cobrir toda a população; (2) nas dificuldades de socialização e adaptação dos estudantes aos contextos urbanos, durante o período em que devem residir na cidade; e (3) na falta de sensibilidade por parte dos docentes que não se interessaram e não têm atuado com grupos marginalizados, apresentando alguns comportamentos baseados em estereótipos ou preconceitos etc. (Knapp, 2018). Essas situações fazem com que muitos dos aspectos que contribuiriam para a consolidação e o sucesso do projeto intercultural da Unir não estejam sendo trabalhados de maneira enfática. Isso demonstra também que integrar grupos minoritários não tem sido uma prioridade para os governos.

Por outro lado, se nos referirmos a uma escala mais concreta, descobrimos que, como parte das tensões e dos questionamentos sobre o exercício intercultural do ensino superior, pontualmente sobre a prática pedagógica de programas pensados desde e para as populações indígenas, têm se repensado alguns eixos de ensino/aprendizagem que revelam as seguintes potencialidades para continuar trabalhando nos avanços citados no parágrafo anterior: (1) o reconhecimento das racionalidades indígenas, diretamente ligadas a um campo espiritual e emocional; (2) a ênfase na construção de conhecimentos coletivos; (3) a valorização da oralidade como possibilidade epistemológica; e (4) a integração da natureza como elemento transversal nos processos de aprendizagem (Markus, 2017). Levando em conta que, na perspectiva crítica, a interculturalidade é um complexo emaranhado de situações e atores envolvidos, articulados e desarticulados em diálogos nem sempre claros e isentos de conflitos, esses elementos revelam que, a partir desse projeto, o tratamento da diferença pode ser considerado um fator enriquecedor e não um obstáculo.

Cada uma das situações mencionadas constitui de maneira profunda o que é a formação de professores indígenas, já que estão intrínsecas às decisões e aos atos mais cotidianos daqueles que participam desse campo. Por isso, desde a sua origem, esse curso tem se consolidado a partir da união de forças, inicialmente, ligadas a um compromisso emocional que emerge das relações entre as comunidades e as pessoas envolvidas. A responsabilidade social que movimenta o curso, antes de ser um assunto profissional, está intimamente associada à disposição, ao comportamento e aos vínculos entre aqueles que se articulam, de uma maneira ou de outra, a esse projeto, incluindo professores, pesquisadores, líderes, estudantes etc.

Desse modo, pode-se dizer que:

[...] as licenciaturas interculturais são recentes, logo, todas as ações ainda estão em processo dinâmico de reflexão para acertar uma formação de professores autônomos e comprometidos com as práticas que valorizem sua cultura. (Couto, [2018], p. 69).

Assim, o caminho para o posicionamento de uma abordagem intercultural crítica que oriente o curso em sua totalidade ainda está sendo forjado. 


\section{Considerações finais}

O ingresso de estudantes indígenas nas universidades gerou profundas tensões e convidou a reconsiderar o ensino superior, o que implicou questionar as estruturas burocráticas e centralizadoras a partir das quais se fundamenta e repensar e consolidar novas disciplinas, conteúdos curriculares, grupos de pesquisa e métodos de avaliação de aprendizagem. Segundo as informações apresentadas ao longo do artigo, esse processo tornou visível alguns referentes lógicos mediante os quais se cimentam os métodos educacionais próprios ou tradicionais e possibilitou que as comunidades participassem ativamente de encontros e experiências que consolidavam espaços que até então lhes eram inacessíveis.

Assim, a formação superior de professores indígenas fortalece uma luta política histórica dos povos originários. Por meio dela, ressurgem processos de reivindicação educacional e cultural, com verdadeiras implicações sociais, já que, além de oferecer a possibilidade de educar em níveis mais altos os professores responsáveis pelo ensino nas escolas das aldeias, contribui para a autonomia das educações próprias e, consequentemente, para o empoderamento dessas populações. Isso se deve ao fato de que, pela apropriação de ferramentas jurídicas e acadêmicas, os professores e as lideranças indígenas vêm trabalhando para estabelecer mecanismos democráticos que garantam o aumento e a eficácia de sua participação em diferentes esferas da vida social.

Sem dúvida, várias das situações e características assinaladas do curso e das licenciaturas interculturais em geral são expressões de certos desafios que a presença indígena trouxe para as universidades. Devido à identificação dos potenciais dessa experiência, os programas com esse enfoque que atualmente estão em andamento no País conseguiram avançar em alguns dos objetivos do movimento que tem promovido a busca por uma justiça epistemológica e cultural para esses povos. No entanto, apesar dos esforços comunitários e institucionais feitos para instaurar e manter tanto as cotas específicas em cursos de graduação convencionais quanto as licenciaturas para a formação de professores indígenas, as decisões que determinam a estabilidade desses projetos estão fortemente sujeitas a uma ordem de pensamento colonial dominante que se reflete em interesses e prioridades governamentais do momento.

Levando em conta que esses cursos são parte da extensa variedade de experiências de formação do ensino superior intercultural, no nível institucional ainda existem várias falências que dificultam a forma de proceder das universidades para garantir a inclusão e a democratização do ensino superior. Em conformidade com dados e análises apresentados e com o suporte do Cres (2018), algumas dessas falências mais relevantes são: (1) a escassez de flexibilidade dos procedimentos administrativos que afetam a alocação de recursos e, portanto, a execução de atividades e projetos nas IES; (2) a rigidez de certos critérios acadêmicos relacionados aos procedimentos de avaliação e credenciamento, que dificultam a participação dos indígenas em distintos cenários, principalmente para os homens 
e mulheres sabedores, que não tiveram uma educação formal prévia; (3) poucos empregados capacitados para trabalhar nesses tipos de contextos desafiadores, o que atrasa o processo de incorporação de conhecimentos, idiomas, pedagogias, valores culturais etc.

Segundo as noções e os pilares do referente conceitual citado, esses aspectos demonstram que o projeto da interculturalidade no ensino superior ainda tem muitas dimensões estruturais não apenas por atender senão por fortalecer desde a institucionalidade. Como se evidenciou, a formação de professores indígenas, especialmente no caso do curso de licenciatura intercultural da Unir, tem imensos potenciais de caráter social para continuar explorando. Porém, o projeto requer uma articulação com todos os níveis de ensino e com as iniciativas governamentais, para conseguir uma continuidade maior e enriquecer ainda mais outras experiências que compõem a existência e a vida em sociedade.

Desse modo, é visto que, apesar da aprovação de leis, políticas e programas institucionais no decorrer do ensino superior intercultural, não se tem garantido, em termos de participação acadêmica, o acesso dos povos indígenas às instituições universitárias, pois, mesmo com avanços na quantidade de cotas ofertadas e abertura de cenários que, anteriormente, eram considerados distantes e alheios das suas realidades, para grande parte deles esse objetivo continua sendo difícil de alcançar. Assim, as conquistas obtidas até hoje só podem nos inspirar para seguir fazendo justiça a essa luta obstinada e perseverante do movimento indígena de Rondônia e do País inteiro.

\section{Referências}

ABRANTES, C.; ISIDORO, E. Uma análise sociolinguística do Projeto Açaí: a formação dos professores Tupi-Mondé de Rondônia, percepções e temperamento linguístico. In: CABRAL; A. S. A. C. et al. (Org). Línguas e culturas Tupi; línguas e culturas Macro-Jê. Brasília, DF: UnB, 2011.

ALVES, I. Identidades indígenas: um olhar para o curso de licenciatura em educação básica intercultural de Rondônia. Porto Velho, RO. 2014. 124 f. Tese (Mestrado em Educação) - Departamento de Ciências da Educação, Universidade Federal de Rondônia, Porto Velho, RO, 2014.

BRASIL. Lei n ${ }^{\circ} 9.394$ de 20 de dezembro de 1996. Estabelece as diretrizes e bases da educação nacional. Diário Oficial da União, Brasília, DF, 23 dez. 1996. Seção 1, p. 27833.

BRASIL. Ministério da Educação (MEC). Conselho Nacional de Educação (CNE). Conselho Pleno (CP). Resolução no 1 , de 7 de janeiro de 2015. Institui Diretrizes Curriculares Nacionais para a Formação de Professores Indígenas em cursos de Educação Superior e de Ensino 
Médio e dá outras providências. Diário Oficial da União, Brasília, DF, 8 jan. 2015. Seção 1, p. 11.

COUTO, F. Reflexões acerca da área de linguagens do curso de educação básica intercultural da UNIR. In: MARTINS, A. M. S. et al. (Org.). Licenciaturas interculturais indígenas: a área de linguagens e suas interfaces. Paraná, RO: Departamento de Educação Intercultural da Fundação Universidade Federal de Rondônia, [2018]. p. 52-69.

CONFERENCIA REGIONAL DE EDUCACIÓN SUPERIOR DE AMÉRICA LATINA Y EL CARIBE (CRES), 3., 2018, Córdoba. Resúmenes ejecutivos...Córdoba: Organización de las Naciones para la Educación, la Ciencia y la Cultura, 2018.

FREITAS, E. B. Índios isolados: a GRIN e a tradição militar da política indigenista brasileira. 1999. Tese (doutorado em História Social) Universidade de São Paulo, São Paulo, 1999.

FUNDAÇÃO UNIVERSIDADE FEDERAL DE RONDÔNIA (UNIR). Departamento de Educação Intercultural (DEINTER). Edital $n^{\circ} 1$, de 15 de dezembro de 2014. Processo seletivo discente DEINTER 2015. Paraná, RO: UNIR, 2014. Disponível em: <http://www.processoseletivo. Unir.br/uploads/certame/119_edital_processo_seletivo_discente.pdf $>$. Acesso em: 9 jun. 2021.

FUNDAÇÃO UNIVERSIDADE FEDERAL DE RONDÔNIA (UNIR). Departamento de Educação Intercultural (DEINTER). Edital $n^{\circ} 1$, de 23 dezembro de 2019. Processo seletivo discente DEINTER 2019. Paraná, RO: UNIR, 2019. Disponível em: <http://www.processoseletivo. Unir.br/uploads/certame/Edital_001_2019_Processo_Seletivo_ DEINTER_584096988.pdf $>$. Acesso em: 9 jun. 2021.

FUNDAÇÃO UNIVERSIDADE FEDERAL DE RONDONIA (UNIR). Projeto Pedagógico do Curso: licenciatura em educação básica intercultural. Universidade Federal de Rondônia. Paraná, RO: UNIR, 2008a. Disponível em: <https://ensinosuperiorindigena.files.wordpress.com/2012/01/pppli-Unir.pdf >. Acesso em: 9 jun. 2021.

FUNDAÇÃO UNIVERSIDADE FEDERAL DE RONDONIA (UNIR). Conselho Superior Acadêmico (CONSEA). Resolução no 198, de 18 de novembro de 2008. Projetos Políticos Pedagógicos. Paraná, RO: UNIR, 2008b. Disponível em: <http://www.biblioteconomia.unir.br/ portal/wp-content/uploads/2015/01/Resolução-198-CONSEA-de-18-denovembro-de-2008.pdf >. Acesso em: 10 jun. 2021.

INSTITUTO BRASILEIRO DE GEOGRAFIA E ESTATÍSTICA (IBGE). População indígena é de 896, 9 mil, tem 305 etnias e fala 274 idiomas. [Brasília, DF], 10 ago. 2012. Disponível em: <https://censo2010.ibge. 
gov.br/noticias-censo $?$ busca $=1 \&$ id $=3 \&$ idnoticia $=2194 \& \mathrm{t}=$ censo-2010poblacao-indigena-896-9-mil-tem-305-etnias-fala-274\&view $=$ noticia $>$. Acesso em: 9 jun. 2021.

\section{INSTITUTO BRASILEIRO DE GEOGRAFIA E ESTATÍSTICA (IBGE).}

Rondônia. [Brasília, DF], [2018]. Disponível em: <https://www.ibge.gov. br/cidades-e-estados/ro.html?>. Acesso em: 9 jun. 2021.

ISIDORO, E. A. Situação sociolinguística do povo arara: uma história de luta e resistência. 2006. 138 f. Dissertação (Mestrado em Letras) Faculdade de Letras, Universidade Federal de Goiás, 2006.

KNAPP, C. Reflexões sobre os estudantes indígenas e a pós-graduação. In: MARTINS, A. M. S. et al. (Org.). Licenciaturas interculturais indígenas: a área de linguagens e suas interfaces. Paraná, RO: Departamento de Educação Intercultural da Fundação Universidade Federal de Rondônia, [2018]. p. 149-176.

LIMA, A. Educación superior para indígenas en el Brasil: más allá de los cupos. In: GARCIA, S.; PALADINO, M. (Org.). Educación escolar indígena: investigaciones antropológicas en Brasil y Argentina. Buenos Aires: Antropofagia, 2012. p. 257-277.

MARKUS, C. Experiências em educação escolar indígena e intercultural: casos concretos. In: LANDA, M; HERBETTA, A. (Org.). Educação indígena e interculturalidade: um debate epistemológico e político. Goiânia: Imprensa Universitária, 2017. p. 316-348.

NEVES, J. Universidade e povos indígenas: a possibilidade do diálogo intercultural na floresta. In: AMARAL, N. G. do. Multiculturalismo na Amazônia: o singular e o plural em reflexão e ações. Curitiba: CRV, 2009.

NEVES, J. O curso de licenciatura intercultural na UNIR: historiografando interculturalidade. In: NEVES, J. G. et al. (Org.). Escolarização, cultura e diversidade: percursos interculturais. Porto Velho, RO: Editora da Universidade Federal de Rondônia, 2013.

PALADINO, M.; ALMEIDA, N. Entre a diversidade e a desigualdade: uma análise das políticas públicas para a educação escolar indígena no Brasil dos governos Lula. Rio de Janeiro: Contra Capa Livraria, 2012.

\section{PROGRAMA DAS NAÇÕES UNIDAS PARA O DESENVOLVIMENTO} (PNUD). Plano Agropecuário e Florestal de Rondônia (PLANAFORO). Proposta curricular de formação de professores indígenas para o magistério: projeto de educação diferenciada e bilíngue: formação de professores indígenas e assessoria às escolas indígenas. [S.l.]: Organização das Nações Unidas, [1995]. 
REVISTA GESTÃo UNIVERSITÁRIA. Projeto Açaí forma professores indígenas em Rondônia. Porto Velho, RO, 8 jul. 2004. Disponível em: <http://gestaouniversitaria.com.br/artigos/projeto-acai-formaprofessores-indigenas-em-rondonia. Acesso em: 9 jun. 2021.

RONDÔNIA. Decreto $n^{\circ}$ 8.516, de 15 de outubro de 1998. Institui o Curso de Formação de Professores Indígenas - habilitação em Magistério nível médio, denominado Projeto Açaí, e dá outras providências. Diário Oficial de Rondônia, Porto Velho, RO, 16 out. 1998.

RONDÔNIA. Secretaria de Estado de Educação (SEDUC). Programa de Desenvolvimento do Ensino Fundamental: Projeto de Educação Escolar Indígena (PEEI): Projeto Açaí. Porto Velho, RO: SEDUC, 2004.

RONDÔNIA. Secretaria de Estado da Educação (SEDUC). Projeto Açaí II forma 70 professores indígenas; eles estão aptos a lecionar para as séries iniciais. Porto Velho, RO, 27 de maio de 2014a. Disponível em: <http:// www.rondonia.ro.gov.br/projeto-acai-ii-forma-70-professores-indigenaseles-estao-aptos-a-lecionar-para-as-series-iniciais/ >. Acesso em: 9 jun. 2021.

RONDÔNIA. Secretaria de Estado da Educação (SEDUC). Projeto Açaí forma 98 professores indígenas em Rondônia. Porto Velho, RO, 27 de maio de 2014b. Disponível em: <http://www.rondonia.ro.gov.br/projetoacai-forma-98-professores-indigenas-em-rondonia/ $>$. Acesso em: 9 jun. 2021.

VENERE, M. Projeto Açaí: uma contribuição à formação dos professores indígenas no estado de Rondônia. 2011. 204 f. Tese (Doutorado em Educação) - Universidade Estadual Paulista, Faculdade de Ciências e Letras de Araraquara, 2011.

WALSH, C. Interculturalidad, plurinacionalidad y decolonialidad: las insurgencias político-epistémicas de refundar el Estado. Tabula Rasa, Bogotá, n. 9, p. 131-152, jul./dic. 2008.

WALSH, C. Interculturalidade, crítica e pedagogia decolonial: insurgir, reexistir e re-viver. In: CANDAU, Vera Maria (Org.) Educação intercultural na América Latina: entre concepções, tensões e propostas. Rio de Janeiro: 7 Letras, 2009.

Recebido em 17 de abril de 2020.

Aprovado em 27 de abril de 2021. 